\title{
Teorias de mercado e regulação: por que os mercados e o governo falham?
}

\section{Market theories and regulation: why do markets and governments fail?}

\author{
Dimária Silva e Meirelles ${ }^{*}$
}

\begin{abstract}
Resumo
Via de regra, a regulamentação, inspirada na teoria econômica neoclássica, é uma resposta às falhas de mercado, que consistem em discrepâncias em relação ao ideal de um mercado competitivo, principalmente, nos setores de bens públicos. É curioso notar que a regulamentação também está sujeita a falhas, denominadas falhas de governo. Afinal, por que o mercado e o governo falham? A resposta a essa questão envolve uma discussão conceitual profunda sobre mercado e competição.

O objetivo deste artigo é apresentar o debate teórico em torno das abordagens de mercado, principalmente, no campo heterodoxo, em que se incluem a visão da economia evolucionária, a da escola austríaca e a da sociologia econômica moderna. A conclusão é que a teoria neoclássica, comparativamente a essas visões, apresenta uma perspectiva limitada do processo de competição.
\end{abstract}

Palavras-chave: competição; regulação; teorias de mercado.

\begin{abstract}
As a rule regulation, inspired by neoclassical economics, is a response to market failures, which are in disagreement with the ideal of a competitive market, especially in the sectors of public goods. It is interesting to note that regulation is also subject to failures, called government failures. After all, why do markets and governments fail? The answer to this question involves a deep conceptual discussion on markets and competition. The aim of this paper is to present the theoretical debate surrounding market approaches, especially in the heterodox field, which include the views of evolutionary economics, Austrian school and the modern economic sociology. The conclusion is that the neoclassical theory, compared to these approaches, has a restricted view of the competition process.
\end{abstract}

Key words: competition; regulation; market theories.

\section{Introdução}

A relação entre governo e mercado está presente, direta ou indiretamente, nas várias atividades econômicas. Conforme assinala Nelson (2002), é enganoso acreditar que existem estruturas governadas essencialmente pelo mercado. As interfaces público-privado podem se dar tanto no âmbito da oferta quanto no da demanda. As políticas públicas, a tributação e a própria moeda são meios a partir dos quais o governo interfere e participa das atividades de mercado.

No caso do setor de serviço, a atuação governamental é marcante, seja ofertando diretamente serviços - como defesa, justiça e administração pública em geral - ou regulamentando a oferta e o uso. Destacam-se nesses casos os serviços de saúde, de intermediação financeira e os de infraestrutura, como telecomunicações e fornecimento de energia elétrica, abastecimento de água e saneamento básico, entre outros. Embora os dispositivos e as normas de regulamentação variem entre tais segmentos, normalmente, são atividades sob constante avaliação e interveniência do governo.

Artigo submetido em maio e aceito para publicação em outubro de 2010

* Doutora em Economia Industrial e da Tecnologia pelo Instituto de Economia da Universidade Federal do Rio de Janeiro; Professora do Programa de Pós Graduação em Administração da Universidade Presbiteriana Mackenzie. Universidade Presbiteriana Mackenzie Centro de Ciências Sociais e Aplicadas. R. da Consolação, 896 - Prédio 29. CEP: 01302-907 - Consolação - São Paulo-SP E-mail: dmeirelles@gmail.com. 
Via de regra, a regulação, inspirada na teoria econômica neoclássica, é desenhada como resposta às falhas de mercado, que consistem em discrepâncias em relação ao ideal de um mercado competitivo, principalmente, nos setores de bens públicos. É curioso notar que a regulação também é sujeita a falhas, denominadas "falhas de governo"; ou seja, o governo falha na tentativa de corrigir as falhas de mercado.

De acordo com Resende (1997), as falhas de governo se devem a três aspectos: a assimetria de informações, os custos de transação e as restrições administrativas e políticas. Nota-se que frequentemente a firma regulada possui mais informações que o regulador quanto à sua estrutura de custos e ao seu nível de eficiência produtiva, o que gera incertezas quanto à definição de tarifas. Além de incertezas, a assimetria de informações gera custos de transação, associados à implementação e ao monitoramento dos contratos. As restrições administrativas e políticas da ação do regulador incluem questões como: rigidez de procedimentos administrativos, dificuldades referentes à definição das esferas de atuação de diferentes agências governamentais e, até mesmo, ingerências de caráter político.

O pressuposto de falhas de mercado, assim como as falhas de governo, suscita questionamentos. Afinal, por que o mercado falha? Mais especificamente: O mercado falha? Será que as falhas de governo não estão relacionadas à dinâmica própria do funcionamento do mercado? A resposta a essas questões envolve discussões conceituais profundas sobre mercado e competição.

O conceito de mercado na visão neoclássica é essencialmente abstrato, desprovido de qualquer conteúdo político e sociológico (SWEDBERG, 1994). Além disso, essa abstração camufla as relações público-privadas, fazendo parecer que seja possível a existência de mercados totalmente organizados (NELSON, 2002).

Reflexões teóricas sobre o conceito de mercado no campo heterodoxo, que envolvem os pontos de vista da economia evolucionária, da escola austríaca e da sociologia econômica moderna, proporcionam uma perspectiva mais concreta do funcionamento do mercado. São visões em que as relações entre governo e mercado são mais a regra do que a exceção, ou meras condições de contorno.

O objetivo do artigo é apresentar estas visões, incluindo a própria visão da economia neoclássica, e o debate teórico em torno do conceito de mercado. Espera-se que esta reflexão proporcione uma melhor compreensão das relações público-privado.

O artigo está estruturado em quatro seções e uma conclusão, além desta introdução. Na primeira seção é apresentada a visão do mercado como lócus da eficiência, representada pela teoria econômica neoclássica e suas extensões: a economia dos custos de transação (ECT) e nova economia institucional (NEI). Apesar de abordarem aspectos distintos do mercado, essas teorias estão baseadas no critério da eficiência, seja ela alocativa, definida a partir de critérios técnicos de combinação e uso eficiente dos recursos, ou transacional, definida pelos custos de transação e pelas instituições.

A teoria econômica neoclássica é apresentada a partir, especificamente, da perspectiva marginalista presente na visão de Walras (1996), já que, Marshall, sobretudo, na sua obra Industry and trade, apresenta uma visão do mercado como um fenômeno empírico. Conforme aponta Swedberg (1994), Marshall identifica uma série de aspectos importantes na compreensão dos mercados, como: espaço, tempo, regulação formal e regulação informal, além de familiaridade entre compradores e vendedores.

A ECT é aqui abordada tendo como base dois autores: Coase (1993) e Williamson (1985, 1991). A nova economia institucional tem como expoente North (1990). De acordo com Swedberg (1994), no âmbito da teoria econômica, as visões de Coase e North são as que apresentam maior contribuição para uma teoria social dos mercados. A primeira, porque define o mercado como uma "instituição social que facilita a troca" (COASE, 1988). A segunda, porque define o mercado como uma "instituição social distinta" (NORTH, 1990).

A segunda seção contempla as visões do mercado como espaço das estratégias e, portanto, como espaço da descoberta e da inovação. É uma perspectiva que enfatiza a mudança e o dinamismo do mercado. Compartilham dessa visão, autores da economia evolucionária (DOSI, 1984; HODGSON, 1988; NELSON; 
WINTER, 1982) e alguns autores da escola austríaca (HAYEK, 1941, 1945; KIRZNER, 1966, 1973; LACHMAN, 1978).

Na terceira seção é apresentada a visão do mercado como espaço sociopolítico, defendida por autores de sociologia econômica como Bourdieu (2005), Fligstein (1996) e Swedberg (1994).

Na quarta seção é apresentada uma síntese das visões de mercado apresentadas e, por fim, na conclusão, são avaliados em que medida os vários aspectos do mercado e do processo competitivo apontados permitem inferir algumas contribuições para a regulamentação dos mercados.

\section{Mercado como lócus da eficiência: a visão neoclássica e a neoinstitucionalista da economia}

Na visão neoclássica, o mercado funciona de forma eficiente quando consegue utilizar os insumos da melhor maneira possível, extraindo-se o máximo de produção ao mínimo custo. Configura-se nesse caso uma situação de competição perfeita, na qual o preço eficiente é aquele onde o custo marginal é igual à receita marginal.

A eficiência é obtida a partir de alguns pressupostos básicos:

- agentes racionais e de comportamento maximizador;

- informação completa e acessível a todos os agentes; e

- grande quantidade de agentes econômicos, produtores e consumidores, os primeiros maximizando lucro e os outros maximizando satisfação (utilidade).

De posse de todas as informações necessárias, a interação desses agentes racionais, objetivando a satisfação de seus interesses e coordenada pelo sistema de preços, resultará em bem-estar para todos, configurando uma situação de equilíbrio geral, em que todos os mercados funcionam em competição perfeita.

Nas situações em que o mercado por si só não consegue estabelecer o preço e a quantidade para gerar eficiência, surgem falhas de mercado. Nessas situações, o governo atua através de regulamentação, visando garantir a alocação eficiente.

Entre as falhas de mercado, destacam-se: o monopólio natural, as externalidades positivas e os bens públicos.

O monopólio natural existe quando, devido a economias de escala, uma firma pode produzir para todo o mercado com um custo menor por unidade que duas ou mais firmas. Apenas uma empresa consegue ser eficiente explorando economias de escala. Em função do comportamento sempre decrescente dos custos, a empresa que opera no mercado tende a explorar o poder de monopólio praticando preços acima do nível de eficiência (o preço de mercado é maior que o custo marginal). Nesse caso, existem duas alternativas para levar o mercado mais próximo da eficiência econômica: a regulamentação e a propriedade pública. Como se pode observar na figura 1, a seguir, a regulamentação do preço se faz necessária para evitar que o preço cobrado não seja abusivo $(\mathrm{Pm})$ e, ao mesmo tempo, para que não torne inviável a produção; ou seja, o preço praticado não cobre todos os custos $(\mathrm{Pc})$. Nesses casos, a regulamentação tende a se dar no nível do custo médio (Pr). 


\section{Figura 1 - Regulamentação do preço do monopólio natural}

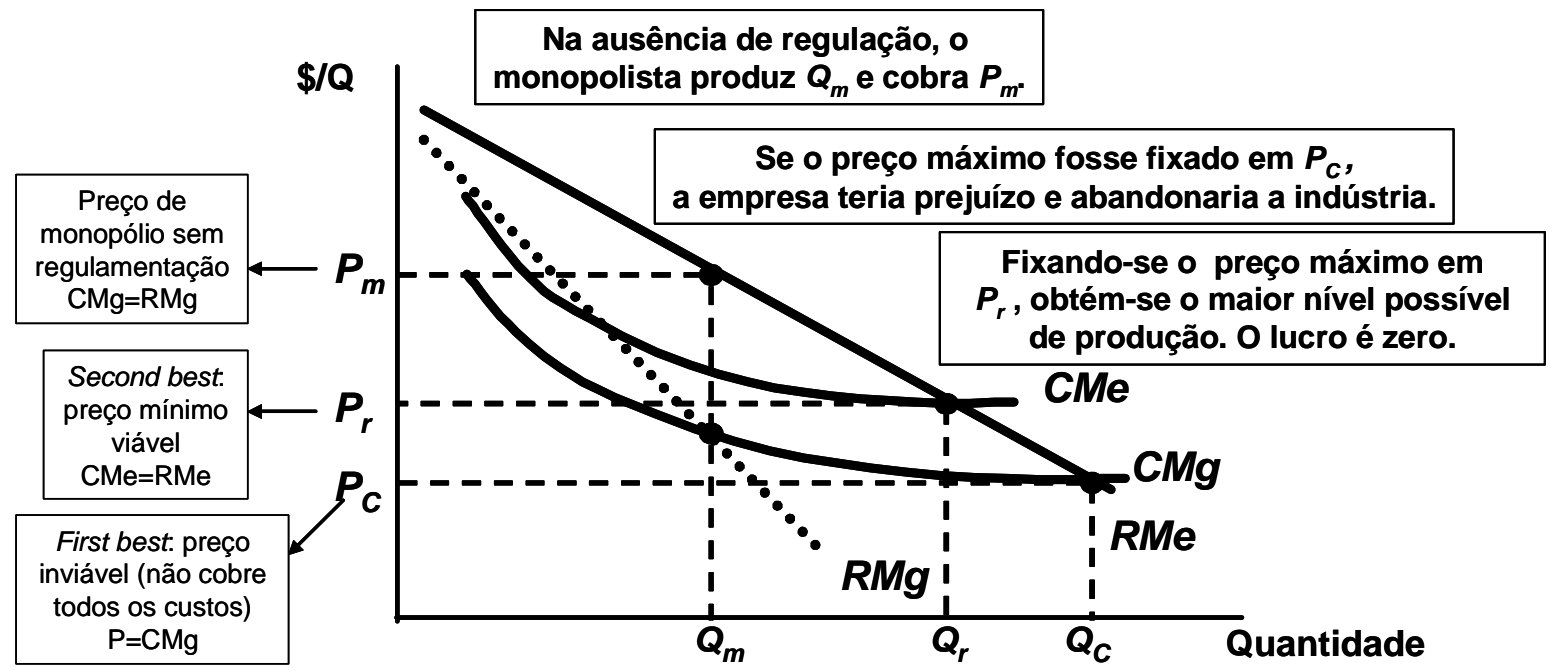

Fonte: Pindick e Rubinfeld (2006, p.308).

As externalidades positivas constituem também outra falha de mercado fortemente associada aos serviços de infraestrutura. Elas são definidas como um subproduto de um bem ou atividade que afete positivamente alguém ou alguma empresa não imediatamente envolvida na transação. No equilíbrio do mercado, o nível de produção eficiente é atingido quando o preço do produto é igual ao benefício marginal social. Quando ocorrem externalidades positivas, o benefício marginal social é maior do que o benefício marginal privado.

As externalidades negativas ocorrem quando as ações de algum indivíduo ou empresa impõem custos a outro indivíduo ou empresa. O nível de produção eficiente é atingido quando o preço do produto é igual ao custo marginal social. Quando ocorrem externalidades negativas, o custo marginal social é maior que o custo marginal privado. Em outros termos, o custo médio social será inferior ao custo médio da produção. Nesse caso, algumas empresas permanecem no setor, mesmo que sua saída seja mais eficiente.

Além das externalidades positivas, os serviços de infraestrutura envolvem outra falha de mercado, que é a natureza do serviço público. As falhas associadas a um bem público decorrem do fato deste não ser competitivo e de ser não excludente. Um bem não competitivo (ou não rival) implica o fato de que o custo marginal de provê-lo para um consumidor adicional seja zero em qualquer nível de produção. Por outro lado, a não exclusão significa que os consumidores têm um incentivo para usufruírem esse bem, gratuitamente, deixando que outros paguem por ele (free riders).

As falhas associadas à natureza de bens públicos desestimulam os investimentos e, nesse caso, o governo atua através do estabelecimento de metas de expansão ou de universalização do serviço público.

Embora baseada em alguns pressupostos distintos da teoria econômica neoclássica, como a racionalidade limitada, a visão da economia neoinstitucional é considerada uma extensão sua extensão, na medida em que o conceito de eficiência é mantido. Enquanto na economia neoclássica o conceito de eficiência é uma questão essencialmente de combinação ótima dos recursos produtivos existentes, de modo a proporcionar a máxima produção e o máximo lucro para as firmas, na visão neoinstitucional a eficiência econômica é explicada em função dos aspectos organizacionais e de coordenação desses recursos, enfatizando-se os chamados "custos de transação". A hipótese subjacente é que, para produzir determinado bem ou serviço, é necessário, antes de tudo, adquiri-los no mercado ou internamente à firma, como normalmente ocorre na aquisição do insumo trabalho. 
A firma deixa de ser apenas um espaço de transformação de insumos em bens ou serviços e passa a ser vista como um espaço de coordenação das ações dos agentes econômicos, ou seja, um nexo de contratos. Nesse processo de contratação e coordenação são gerados custos de transação, relacionados à negociação, ao monitoramente e à execução de contratos, além dos custos associados às rupturas e falhas do próprio contrato (COASE, 1993).

Deve ser observado, portanto, que os custos de transação não são diretamente ligados à produção. São custos que surgem à medida que os agentes se relacionam entre si e emergem problemas de coordenação de suas ações. Nesse sentido, a busca da eficiência deve seguir também a lógica da redução dos custos de transação. A eficiência não é uma consequência automática das condições tecnológicas e de escala nas quais a empresa opera. Na verdade, a eficiência está relacionada também às interações e relações contratuais que a empresa estabelece com o ambiente onde está inserida; ou seja, a eficiência transacional é parte importante na tomada de decisões.

Na visão da economia dos custos de transação, que tem como expoente Williamson (1985), dois pressupostos são fundamentais para o entendimento das transações: a racionalidade limitada e o comportamento oportunista dos agentes. Em função da racionalidade limitada os contratos são incompletos; sendo incompletos, eles implicam renegociações futuras. Nessas renegociações, o oportunismo dos agentes pode impor perdas à sua contraparte na transação. Nesse contexto, os agentes buscam se proteger através de salvaguardas e de mecanismos de incentivo que contornem as práticas oportunistas.

Em resumo, as transações sempre envolvem custos de transação, custos estes que tendem a ser mais elevados quanto maior a possibilidade de contingências, posto que aumenta a probabilidade de comportamentos oportunistas. Do ponto de vista da eficiência transacional, portanto, há que se criar mecanismos de adaptação ao permanente esquema conflitivo presente nas relações contratuais, de modo a proporcionar a máxima eficiência. Esses mecanismos variam de acordo com a natureza das transações, ou seja, conforme a dimensão das relações contratuais.

São três as dimensões das transações: especificidade de ativos, frequência e incerteza. O grau em que essas dimensões se manifestam nas transações econômicas implica diferentes desenhos de soluções eficientes, i.e., estruturas de governança que atenuam os custos de transação associados. Essas soluções vão desde as transações instantâneas de mercado, passando pelas formas híbridas, até a internalização das transações (integração vertical e/ou horizontal).

A especificidade está relacionada ao uso específico que se faz do ativo na transação. Ativos específicos são aqueles cujo valor é dependente da continuidade da transação à qual ele é específico. Por depender da continuidade da transação, trata-se de um conceito indissociável do tempo. Essa característica, aliada ao pressuposto do oportunismo e incompletude dos contratos, torna o investimento nesses ativos sujeito a riscos e problemas de adaptação, gerando custos de transação. Quanto maior a especificidade, maiores serão os riscos e os problemas de adaptação e, portanto, maiores os custos de transação.

Ao tomar as dimensões das transações como parâmetro, Williamson propõe dois modelos de análise da eficiência relativa das diferentes estruturas de governança para cada tipo de transação: 1) o modelo analítico reduzido (WILLIAMSON, 1985, 1991), em que a variável-chave é a especificidade dos ativos; e 2) o modelo principal (RIORDAN; WILLIAMSON, 1985), em que os custos de transação e custos de transformação são tratados conjuntamente na definição do ponto de máxima eficiência. Nesses modelos, as variáveis explicativas são as dimensões das transações e a variável dependente é o custo de governança; ou seja, o custo associado a uma determinada forma organizacional.

Assumindo que o objetivo da firma é o máximo lucro, a forma organizacional escolhida é aquela que proporciona a maior diferença entre receita total e custos totais, incluindo o custo relacionado à especificidade do ativo e o custo de governança associado à estrutura organizacional em questão. 
O lucro $(\pi)$ no modelo principal seria, então, função de três variáveis: quantidade $(\mathrm{Q})$, especificidade de ativos $(\mathrm{k})$ e um vetor de parâmetros de deslocamento $(\theta)$, descontados os custos de governança $(\beta)$ :

$\pi(\mathrm{Q}, \mathrm{k}, \theta)=\mathrm{R}(\mathrm{Q})-\mathrm{C}(\mathrm{Q}, \mathrm{k}, \theta)-\alpha \mathrm{k}-\beta$,

onde: $\mathrm{R}(\mathrm{Q})=$ receita total de vendas

Conforme é observado na figura 2, o processo de escolha pode ser representado por diversas funções de lucro em cada forma organizacional: mercado $(\mathrm{M})$, hierarquia $(\mathrm{H})$ e forma híbrida $(\mathrm{X})$. Para um dado nível de produção, a escolha da forma organizacional deverá variar conforme os custos de governança ( $\beta$ ). Supondo um nível de custos $\beta_{0}$, a forma organizacional que proporciona o máximo lucro é a hierárquica $\left(\pi_{\mathrm{H}}\right)$. Entretanto, para um custo de governança superior $\left(\beta_{1}\right)$, a forma híbrida tenderá a ser a escolhida, pois irá proporcionar um lucro maior $\left(\pi_{\mathrm{x}}\right)$ :

\section{Figura 2 - Modelo principal: especificidade de ativos e estrutura de governança}

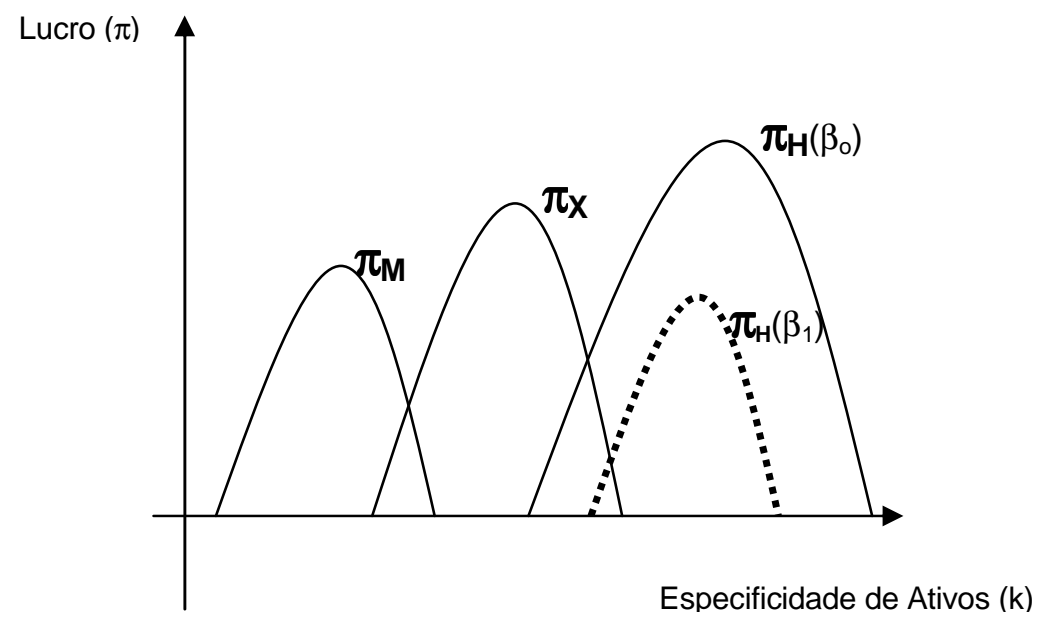

Fonte: Riordan e Williamson (1985, p.372).

Vale lembrar que o papel das demais dimensões das transações, como a incerteza, por exemplo, é distinguir o grau de suscetibilidade de cada estrutura de governança às variações dos eventos. Mudanças no vetor de parâmetros de deslocamento afetam de forma diferenciada as estruturas de governança.

Resumindo, a estrutura de governança tem como função principal a redução dos custos de transação. Quanto maior a especificidade dos ativos, maior a frequência das transações e maior o nível de incerteza, maiores são os custos de transação; portanto, maior é o incentivo à formação de estruturas de governança internas à firma.

Baseado nessa perspectiva neoinstitucionalista, Joskow (1993) analisa a estrutura organizacional do setor elétrico. As transações nesse setor envolvem: um alto grau de especificidade dos ativos e a incerteza e baixa frequência das transações. Tanto a transmissão como a distribuição são caracterizadas por alta especificidade dos ativos e baixa frequência das transações. Uma vez estabelecido um sistema de transmissão ou distribuição, ele tem uma longa vida econômica e as transações são de baixa frequência. A combinação desses fatores gera altos custos de transação que, juntamente com a possibilidade de exploração de economias de escala e escopo, geram um ambiente propício à integração vertical e horizontal nas indústrias de energia elétrica. Vale dizer, o análogo das falhas de mercado na visão da ECT é a integração vertical.

Outra dimensão importante na definição do custo de governança é o ambiente institucional. Embora não tratado diretamente no modelo, essa dimensão é considerada por Williamson e está presente no vetor de parâmetros de 
deslocamento das funções. Elementos institucionais que possibilitam uma redução nos custos de transação, seja de fiscalização de direitos de propriedade, de monitoramento do desempenho, de organização das atividades ou de adaptação são respostas eficientes dos agentes ao problema de se transacionar. Todavia, a abordagem de Williamson (1985) privilegia os custos de adaptação; ou seja, os custos relacionados às práticas oportunistas dos agentes diante das mudanças no ambiente econômico. Daí a ênfase na especificidade dos ativos como variável explicativa fundamental dos custos de transação.

O ambiente institucional é bastante explorado no âmbito da nova economia institucional (NEI), que tem North (1990) como expoente. O autor destaca dois elementos não considerados pela teoria neoclássica, que são as instituições e o tempo, embora mantenha a suposição fundamental de escassez e competição e ferramentas analíticas da microeconomia.

Conforme proposto por North (1990), as instituições constituem as limitações humanamente concebidas que estruturam a interação humana. Elas são feitas de limitações formais (regras, leis e constituições) e de limitações informais (normas de comportamento, convenções e códigos de conduta autoimpostos) e suas características de execução. Em conjunto, estas limitações definem a estrutura de incentivo das sociedades e especificam economias.

É a interação entre instituição e organizações que molda a evolução institucional da economia. Se instituições são as regras do jogo, organizações e seus empresários são os jogadores. Organizações são formadas por grupos de indivíduos que se juntam com o propósito de atingir certos objetivos comuns. Organizações incluem corpos políticos (partidos políticos, Senado, conselhos de cidades, corpos regulatórios), corpos econômicos (empresas, uniões de troca, fazendas familiares, cooperativas), corpos sociais (igrejas, clubes, associações atléticas) e corpos educacionais (escolas, universidades, centros de treinamento vocacional). As organizações que passam a existir refletem as oportunidades providas pela matriz institucional.

Na visão de North, a teoria econômica neoclássica está voltada para o funcionamento do mercado, ou seja, para o modo como este opera e não como se desenvolve. Para o autor, as instituições formam a estrutura de incentivo da sociedade, e as instituições políticas e econômicas, como consequência, são os determinantes subjacentes do desempenho da economia. Tempo, sendo relacionado com mudanças econômicas e societais, é a dimensão com a qual o processo de aprendizagem humana molda o desenvolvimento das instituições. Isto é, as crenças que os indivíduos, grupos e sociedades mantêm, e que determinam suas escolhas, são consequência de um aprendizado acumulado ao longo do tempo e transmitido de uma geração para outra.

Tradicionalmente, os indivíduos agem com base em informações incompletas e em modelos subjetivos frequentemente errôneos. O feeddback de informação é tipicamente ineficiente para a correção desses modelos. As instituições não são necessárias e quando criadas, usualmente, não é para que sejam socialmente eficientes. $\mathrm{Na}$ verdade, são criadas para servir aos interesses dos que têm poder de barganha para criar novas regras (NORTH, 1990).

Todavia, conforme ressaltado por Randles e Warde (2002), a visão de Williamson e North ainda é determinista, privilegiando os agentes individuais e atribuindo a estes um alto nível de racionalidade, um comportamento otimizador e autonomia diante de escolhas estratégicas. No âmbito da economia neoinstitucional, há um grupo de autores, como Alston (1996) e Eggertsson (1996), que se destacam na análise do processo de emergência e mudanças institucionais, incorporando questões relativas ao poder e à existência de relações assimétricas de poder. Nesse sentido, são autores que se aproximam da visão do mercado como espaço sociopolítico, apresentada no item 4 .

\section{Mercado como processo de descoberta e espaço das estratégias: a visão da escola austríaca e a dos evolucionários}

O processo de mercado é tema que marca as obras de grande parte dos autores da escola austríaca. Conforme assinalam Foss et al (2002), ao teorizar sobre o capital, os autores dessa escola, mais especificamente, Hayek 
(1941), Lachman (1978) e Kirzner (1966, 1973), acabam teorizando sobre o funcionamento do mercado e da própria firma.

$\mathrm{Na}$ interpretação de Barbieri (2001), as teorias de processo de mercado na escola austríaca estão preocupadas com "a sequência de eventos que ocorrem no mercado, que pode ou não levar a um estado de equilíbrio". Os agentes são ignorantes em relação à realidade que os cerca. Nessa perspectiva, a preocupação central da teoria de processo de mercado é o processo de aprendizado dos agentes (HAYEK, 1945). O processo de descoberta, de aprendizado, é decorrência do processo de competição.

Nesse processo de descoberta, o empreendedor exerce papel fundamental (KIRZNER, 1973). Partindo de uma abordagem subjetiva, Kirzner enfatiza a heterogeneidade do capital. É nas diferentes interpretações acerca das oportunidades de mercado que surgem as inovações. Perspectiva semelhante sobre o processo de competição, e o papel fundamental do empreendedor na evolução do sistema capitalista, está presente na obra de Schumpeter (1943), considerado um dos autores de referência na visão da economia evolucionária.

De maneira semelhante, sobretudo, em relação ao papel da inovação no processo de competição, os autores da economia evolucionária visualizam o processo de competição numa perspectiva dinâmica, baseada na busca de lucros via inovações. Nessa perspectiva, concorrência não se opõe a monopólio. Na verdade, as posições monopolísticas são vistas como posições temporárias de defesa de lucros extraordinários, resultantes da capacidade de inovação das empresas no processo concorrencial (SCHUMPETER, 1943, 1984).

De acordo com Nelson e Winter (1982, p.39), a análise evolucionária é utilizada para pensar a dinâmica econômica tal como proposta por Schumpeter, para quem o processo de inovação, que resulta na geração de variedade, é a base da competição num sistema capitalista. O funcionamento do mercado, concebido como um ambiente seletivo por excelência, é capaz de induzir e de selecionar inovações organizacionais, de processo e de produto que possam levar a futuras reduções de custos e de preços, bem como a melhorias na qualidade dos produtos; ou seja, de gerar variações.

D’Aveni (1994 apud Langlois, 2001) creditou a Schumpeter e a outros austríacos a noção de hipercompetição, que resulta, segundo o autor, da dinâmica competitiva entre empresas "globais e inovadores combatentes". A frequência, a audácia e a agressividade dos players no mercado acelera a criacão da condição de constante desequilíbrio e mudança. Nesse contexto, a estabilidade de mercado é ameaçada por:

pequenos ciclos de vida de produtos, pequenos ciclos de design de produtos, novas tecnologias, entrada frequente e inesperada de novos competidores de fora do mercado, reposicionamento de incumbents e definição radical de limites de mercado, à medida que indústrias diversas se fundem.

Tanto na perspectiva da escola austríaca quanto na da evolucionária, a ação humana não é guiada pela consciência deliberada, mas sim por regras e rotinas. O conjunto de rotinas (operacionais, de investimento e de busca e inovação) fundamentam as capacidades da firma (NELSON; WINTER, 1982; WINTER, 2003). Aqui, há uma considerável sobreposição às abordagens dadas pela resource based view (RBV) e teoria de capacidades dinâmicas (TEECE et al, 1994; WINTER, 2003) às estratégias. Nessas teorias, vantagem competitiva não é primariamente uma questão de posicionamento estratégico, mas sim, uma questão de se criar competências distintivas.

A diversidade de competências, posto que idiossincráticas às firmas, refletem-se no nível dos mercados. De acordo com Nelson (2002), os mercados são heterogêneos por natureza, pois refletem caminhos particulares de organização da demanda e da oferta. Esses caminhos resultam da ação de mudanças no ambiente tecnológico (DOSI, 1984) combinadas com as próprias rotinas de inovação das firmas (NELSON; WINTER, 1982).

$\mathrm{O}$ estudo da natureza e das origens das instituições de mercado, bem como do seu impacto sobre o comportamento dos agentes, é explorado por autores evolucionários como Hodgson (1988) e Langlois (2001).

Na visão de Hodgson (1988), o sistema socioeconômico é complexo e sua variedade é explicada pela interconexão entre os subsistemas. Nessa perspectiva, ele propõe a substituição da visão atomística do mercado, 
proposta pela economia neoclássica, por uma visão ontológica orgânica, em que os elementos do sistema são produtos das relações com outras entidades. O fenômeno econômico se dá a partir de formas organizacionais sistêmicas. No âmbito dessa complexidade, as instituições desempenham um papel fundamental na determinação e na diferenciação das várias formas organizacionais. Isto é, não existe um mercado livre (ou desregulamentado). Toda forma de mercado é regulada pelas várias instituições que fundamentam a sua existência e reprodução.

Conforme assinala Langlois (2001), a vida econômica é cheia de comportamentos estruturados e recorrentes que podemos chamar de instituições. A complexidade e a variedade de setores e atividades requerem estruturas de governança adequadas, entendidas como o conjunto de instituições que, resumidamente, determinam: o conjunto de valores e interesses envolvidos para a identificação do que será provido e distribuído, as responsabilidades de provisão e o desenho do sistema de incentivos e controles (NELSON, 2002).

\section{Mercado como espaço sociopolítico: a visão da sociologia econômica e a da teoria institucional das organizações}

Partindo das visões de autores da sociologia econômica, como Parsons e Semelser (1956) e Polanyi (1957), alguns autores no campo da sociologia econômica defendem o estudo da diversidade dos modelos de competição (HARVEY, 2002; RANDLES, 2003; SWEDBERG, 1994).

Na visão de Polanyi (1957), a competição econômica é característica de apenas algumas instituições de mercado. Estudos antropológicos realizados pelo autor em diferentes regimes de troca, comércio e alocação permitem identificar diferentes aspectos da dinâmica competitiva. De acordo com Parsons e Semelser (1956), os mercados diferem não só em grau como também pela característica ou perfil sociológico. Em consequência, os mercados, e, por inferência, a competição, são estruturados de maneiras diferentes.

No entanto, segundo Swedberg (1994), é Polanyi (1957), ao desenvolver esforços pelo desenvolvimento de uma sociologia econômica, que apresenta maiores contribuições ao estudo do mercado, principalmente, quando enfatiza o desenvolvimento histórico do mercado moderno a partir de ações políticas, como a criação do Estado mercantilista e a eliminação da regulação de mercado em meados do século XIX.

Segundo Swedberg (1994), há uma evolução no escopo de mercado ao longo da história, e, por conseguinte, do próprio conceito de mercado. Inicialmente, os mercados são apenas espaço de troca. À medida que a tecnologia e as estruturas sociais avançam, principalmente através das revoluções políticas, o escopo dos mercados se amplia e estes passam a estar associados à dinâmica do crescimento econômico. O comportamento competitivo passa a estar enraizado em toda a sociedade. Nesse processo evolutivo, amplia-se o grupo de atores sociais envolvidos e a própria composição da estrutura social do mercado, como o número de compradores e vendedores, se os atores são indivíduos ou organizações e se os atores são organizados.

Seguindo uma linha weberiana de análise do mercado, em que a ação social no mercado começa com competição e termina com troca, para Swedeberg (1994) os mercados variam tanto em relação à competição quanto à troca. A competição seria o conflito pacífico entre as partes, na tentativa de controlar oportunidades e vantagens que também são desejadas por outros. Por sua vez, a troca seria o compromisso de interesses entre as partes, onde mercadorias ou outras vantagens são passadas como compensação recíproca.

Com base nessa perspectiva teórica e histórica, Swedberg (1994) apresenta uma tipologia de mercados como estruturas sociais que evoluem ao longo do tempo. Como se poderá observar no quadro 1 , são identificados oito tipos ideais de mercado: i) mercados pré-históricos (ligados a pequenas comunidades); ii) mercado de trocas a longas distâncias (perto da era cristã); iii) mercado da Idade Média; iv) mercado capitalista moderno; v) mercado de trabalho; vi) mercado de capitais; vii) mercado de consumo; e viii) mercado industrial.

Mercados menos evoluídos são, em geral, menos organizados e estão limitados a um determinado grupo de atores sociais e de produtos vendidos. É o caso dos mercados de longa distância (rotas de comércio), em que a 
competição é limitada aos profissionais do comércio e a um grupo restrito de produtos. Os custos de cumprimento dos contratos (enforcement) também são elevados. Em contraposição, o mercado capitalista moderno apresenta um alto grau de organização das trocas e amplo escopo de competição. $\mathrm{O}$ suporte da máquina do estado às trocas proporciona baixos custos de enforcement.

Quadro 1 - A estrutura social dos mercados históricos (tipos ideais)

\begin{tabular}{|c|c|c|}
\hline MERCADO & COMPETIÇÃO & TROCA \\
\hline $\begin{array}{l}\text { Pré-histórico (como } \\
\text { os espaços de troca } \\
\text { nos limites das } \\
\text { pequenas } \\
\text { comunidades) }\end{array}$ & $\begin{array}{l}\text { Baixa competição, não vai além do } \\
\text { lugar de troca dentro da sociedade. } \\
\text { Poucos atores no mercado }\end{array}$ & $\begin{array}{l}\text { Troca direta (sem moeda) e barganha. } \\
\text { Comportamento hostil em relação a partes de } \\
\text { outras comunidades. Poucos e ineficientes } \\
\text { caminhos para recuperar troca (altos custos de } \\
\text { enforcement, i.e., de cumprimento dos contratos) }\end{array}$ \\
\hline $\begin{array}{l}\text { Mercados de longa } \\
\text { distância (como as } \\
\text { rotas de comércio } \\
\text { para o Oriente na Era } \\
\text { Cristã) }\end{array}$ & $\begin{array}{l}\text { Competição entre profissionais do } \\
\text { comércio (traders e comerciantes). } \\
\text { Troca frequentemente limitada a certo } \\
\text { número de produtos de luxo. } \\
\text { Competição não atinge profundamente } \\
\text { a organização produtiva da sociedade }\end{array}$ & $\begin{array}{l}\text { Há várias e diferentes formas de organizar a troca. } \\
\text { Altos e imprevisíveis custos de enforcement, mas } \\
\text { também altos lucros na troca }\end{array}$ \\
\hline $\begin{array}{l}\text { Mercado da Idade } \\
\text { Média (mercados de } \\
\text { cidades) }\end{array}$ & $\begin{array}{l}\text { Competição local e fortemente } \\
\text { regulada pela cidade. Comportamento } \\
\text { competitivo só alcança parte da } \\
\text { sociedade. Regras econômicas } \\
\text { pautadas pelo tradicionalismo }\end{array}$ & $\begin{array}{l}\text { A barganha é comum e a troca é baseada em } \\
\text { mercadorias ainda não padronizadas (altos custos } \\
\text { de medição). Paz nos lugares de troca, mas os } \\
\text { custos de enforcement ainda são altos }\end{array}$ \\
\hline $\begin{array}{l}\text { Mercado capitalista } \\
\text { moderno (por } \\
\text { exemplo, o mercado } \\
\text { de capitais) }\end{array}$ & $\begin{array}{l}\text { Livre competição (nacional e } \\
\text { internacional). Comportamento } \\
\text { competitivo enraizado em toda a } \\
\text { sociedade (competição tanto no } \\
\text { mercado quanto na produção) }\end{array}$ & $\begin{array}{l}\text { Há vários mecanismos racionais de facilitação da } \\
\text { troca (baixos custos de procura). A barganha é } \\
\text { marginal. Toda a máquina do Estado dá suporte às } \\
\text { trocas (baixos custos de enforcement) }\end{array}$ \\
\hline Mercado de trabalho & $\begin{array}{l}\text { Normalmente, muitos vendedores } \\
\text { (individuais) versus poucos e } \\
\text { poderosos compradores (organizações). } \\
\text { Competição regulada pelas } \\
\text { organizações empregadoras, por } \\
\text { sindicatos e pela legislação. Falta de } \\
\text { mobilidade entre vendedores } \\
\text { frequentemente torna a competição } \\
\text { local }\end{array}$ & $\begin{array}{l}\text { Trocas descentralizadas (altos custos de busca). } \\
\text { Escopo limitado para barganha, devido aos } \\
\text { sindicatos, às organizações empregadoras e às } \\
\text { normas de justiça distributiva. Problemas de } \\
\text { medição devidos à transmissão de direitos } \\
\text { relacionados com a agência, em oposição à } \\
\text { propriedade }\end{array}$ \\
\hline Mercado de capital & $\begin{array}{l}\text { Número limitado de compradores e } \\
\text { vendedores; a maioria, organizações. } \\
\text { Regulação pública e privada. } \\
\text { Intervenções políticas. Competição tem } \\
\text { escopo nacional e internacional }\end{array}$ & $\begin{array}{l}\text { Trocas frequentemente centralizadas na forma de } \\
\text { mecanismos organizados de liquidação (clearing). } \\
\text { Baixos custos de procura. Existem máquinas de } \\
\text { suporte para trocas, mas apenas em nível nacional. } \\
\text { Direitos de propriedade são totalmente transferidos }\end{array}$ \\
\hline Mercado de consumo & $\begin{array}{l}\text { Normalmente, poucos vendedores } \\
\text { (organizações) e muitos compradores } \\
\text { (indivíduos), que não são organizados. } \\
\text { Alguma regulação pública, mas em } \\
\text { vários casos a competição é livre }\end{array}$ & $\begin{array}{l}\text { Preços fixos e nenhuma barganha. Lugares de troca } \\
\text { descentralizados, mas, fixos, resultam em baixos } \\
\text { custos de procura. Direitos de propriedade são } \\
\text { totalmente transferidos }\end{array}$ \\
\hline Mercado industrial & $\begin{array}{l}\text { Comumente, muitos compradores e } \\
\text { vendedores; todos eles são } \\
\text { organizações. Redes de compradores e } \\
\text { de vendedores frequentes nesse tipo de } \\
\text { mercado }\end{array}$ & $\begin{array}{l}\text { A troca frequentemente se dá na forma de } \\
\text { negociações, sendo totalmente descentralizada. } \\
\text { Direitos de propriedade são totalmente } \\
\text { transferidos. As obrigações dos vendedores } \\
\text { permanecem. Altos custos de procura são } \\
\text { frequentes }\end{array}$ \\
\hline
\end{tabular}

Fonte: Swedberg (1994, p.273). 
Nessa perspectiva do mercado como estrutura social, os preços resultam da batalha de poder entre as partes que o compõem (SWEDBERG, 1941). Conforme assinala Bourdieu (2005), "não são os preços que determinam todas as coisas, mas todas as coisas é que determinam os preços".

Baseado numa perspectiva sociopolítica de funcionamento do mercado, de base epistemológica estruturalista, Bourdieu (2005) propõe uma análise da competição a partir da análise das estruturas de capital, que são específicas de cada campo de recursos. Em contraponto à visão neoclássica, o conceito de campo quebra a lógica abstrata de determinação automática, mecânica e instantânea de preços nos mercados onde a competição livre prevalece.

A estrutura do campo, determinada pelas relações de força (ou de poder) entre as firmas, define as condições nas quais os agentes decidem ou negociam preços de compra e venda. Nesse caso, as relações de força incluem não só produtores ocupando diferentes posições na estrutura de capital, como também clientes ocupando posições no espaço social análogas às posições que os produtores ocupam no campo (BOURDIEU, 2005, p.83).

A estrutura de capital confere poder às firmas na medida em que revela controle sobre recursos. Segundo Bourdieu (2005), a estrutura de capital é composta por oito espécies de capital: financeiro, tecnológico, comercial, cultural, jurídico, organizacional, social e simbólico. Dessas espécies, as mais importantes são a financeira, a tecnológica e a comercial.

O capital financeiro, que consiste no conjunto de recursos financeiros controlados direta ou indiretamente (por meio dos bancos), é a principal condição para a acumulação e a conservação de todos os outros tipos de capital. O capital tecnológico, que consiste no portfólio de recursos científicos e técnicos empregados no design e na manufatura de produtos, define o potencial de redução de gastos em capital e trabalho ou o aumento da renda da firma. O capital comercial se relaciona ao controle da rede de distribuição (transporte e armazenamento), comercialização e serviços pós-venda.

Segundo Bourdieu (2005), as várias espécies de capital não atuam apenas indiretamente, através dos preços, mas também exercem um efeito estrutural. Além de conferir poder, a estrutura de capital define os preços de entrada dentro do campo e a distribuição de oportunidades de lucro. A adoção de uma nova tecnologia ou o controle de uma proporção significativa do mercado, por exemplo, promovem mudanças nas posições relativas e no retorno das várias espécies de capital que as firmas detêm.

As forças do campo tendem a reforçar as posições dominantes. Entretanto, as relações de forças do campo mudam. Novos agentes e novas tecnologias podem modificar a estrutura do campo, seja nas posições dentro do campo, seja nas espécies de capital que outras firmas detêm. Nesses casos, o capital tecnológico, de acordo com Bourdieu, desempenha papel fundamental na suplantação das firmas dominantes, embora este só seja efetivo quando associado com os outros tipos de capital.

As mudanças nas posições dentro do campo tendem a se originar mais nas interações externas com outros campos do que internamente. Essas interações são definidas pelo capital social, que consiste na totalidade de recursos - incluindo o capital financeiro - que são mobilizados através de uma rede de relações mais ou menos extensa. Entre as interações externas mais importantes estão aquelas estabelecidas com o Estado. Através do seu capital social, as firmas dominantes pressionam o Estado para modificar as regras do jogo a seu favor (BOURDIEU, 2005, p.81).

A competição entre as firmas toma a forma de competição por poder através do poder do Estado, principalmente, do poder de regulação e do de direitos de propriedade. O Estado, segundo Bourdieu, não é um simples regulador instituído para manter a ordem e a confiança; sua ação contribui decisivamente na construção tanto da demanda quanto da oferta. Nesse sentido, o mercado é a totalidade das relações de troca entre agentes em competição, cuja interação ocorre na forma de um "conflito indireto", a partir da estrutura de relações de força construída socialmente pelos agentes, através do poder de Estado. 
Uma interessante contribuição no campo sociopolítico, que enfatiza o papel do Estado e da interação das corporações na criação dos mercados industriais, é a de Fligstein (1996). O autor propõe um modelo social de ação no qual os participantes do mercado tentam criar mundos estáveis e encontrar soluções sociais para a competição. Partindo de uma abordagem política e cultural, o autor usa a metáfora "mercados como política" para entender como essas estruturas sociais existem, produzem mundos estáveis e são transformadas.

De acordo com Fligstein (1996), as estruturas sociais de mercado e as organizações internas das empresas são melhor vistas como tentativas de mitigar os efeitos da competição com outras firmas. Nessa perspectiva, os processos do mercado refletem dois tipos de projetos políticos: o poder interno da firma em lutar e o poder de luta entre as firmas. O primeiro avalia quem irá controlar a organização, como ela será organizada e como as situações serão analisadas e resolvidas. Os vencedores dessa luta serão os que tiverem a visão de como a firma trabalha internamente e de como a empresa se relacionará com seus principais competidores. Nesse processo, mercados e estados estão intimamente ligados.

A formação de mercados é parte da formação do estado; ou seja, estados modernos com economias capitalistas criam condições institucionais para mercados se estabelecerem. Grandes crises sociais, tais como guerras, depressões ou entrada de uma nação em desenvolvimento moderno são pontos principais para se entender o desenvolvimento da economia de uma sociedade (FLIGSTEIN, 1996).

A produção de instituições de mercado pode ser considerada um projeto cultural de várias maneiras. Direitos de propriedade, estruturas de governança, concepções de controle e regras de troca definem as instituições sociais necessárias para criar mercados. A interação entre Estado e empresa em várias sociedades produziu culturas únicas de produção (FLIGSTEIN, 1996).

Segundo Fligstein (1996), países industriais não estão convergindo em direção a uma única forma. Ao invés disso, uma pluralidade de relações sociais tem sido observada. Essas observações têm desafiado a visão dos economistas neoclássicos de que os mercados selecionam formas eficientes, as quais, ao longo do tempo, convergem para uma única forma.

\section{Síntese das teorias de mercado}

As visões de mercado apresentadas neste estudo podem ser sintetizadas em três perspectivas de análise: mercado como espaço da eficiência, mercado como espaço das estratégias e mercado como espaço sociopolítico. Como se poderá observar no quadro 2, cada uma dessas perspectivas está apoiada em distintos pressupostos teóricos e conceitos de competição.

A visão de mercado como espaço da eficiência inclui tanto a perspectiva de eficiência alocativa da abordagem neoclássica quanto a de eficiência transacional da economia neoinstitucional. Apesar de pressupostos comportamentais diferentes, como a racionalidade limitada e o comportamento oportunista, o conceito de competição, tanto na economia neoclássica quanto na neoinstitucional é o mesmo; ou seja, é definido pelo critério de eficiência. Na economia neoinstitucional o foco está na decisão de internalizar ou não as transações. $\mathrm{O}$ mercado é abordado como contraponto à firma (hierarquia). Quando o mercado é ineficiente - ou seja, quando o mecanismo de preços, como dispositivo de coordenação do mercado, apresenta custos de governança superiores à hierarquia -, a firma substitui o mercado.

Um preço eficiente de mercado é aquele definido no ponto onde o custo marginal é igual à receita marginal, ou seja, onde o custo de se produzir uma unidade adicional de produto ou serviço se iguala à receita obtida com a venda dessa unidade. Nesse nível, o preço é considerado de competição perfeita. Isto é, não há nenhum ganho acima dos lucros econômicos normais. Quando o mercado por si só não consegue estabelecer o preço e a quantidade de concorrência perfeita, configuram-se falhas de mercado. Nessa perspectiva, o conceito de mercado se confunde com o próprio conceito de competição perfeita. 
Quadro 2 - Síntese das visões de mercado e conceitos de competição

\begin{tabular}{|c|c|c|c|}
\hline $\begin{array}{l}\text { VISÃO DE } \\
\text { MERCADO }\end{array}$ & ABORDAGEM/AUTORES & PRESSUPOSTOS & $\begin{array}{l}\text { CONCEITO DE } \\
\text { COMPETIÇÃO }\end{array}$ \\
\hline \multirow{6}{*}{$\begin{array}{l}\text { Mercado como } \\
\text { espaço da } \\
\text { eficiência }\end{array}$} & \multirow{3}{*}{$\begin{array}{l}\text { Economia Neoclássica } \\
\text { (WALRAS, 1996) }\end{array}$} & $\begin{array}{l}\text { O comportamento humano é } \\
\text { racional e maximizador }\end{array}$ & \multirow{2}{*}{$\begin{array}{l}\text { Competição é sinônimo de } \\
\text { eficiência alocativa do mercado }\end{array}$} \\
\hline & & $\begin{array}{l}\text { Informação completa e acessível } \\
\text { a todos os agentes }\end{array}$ & \\
\hline & & $\begin{array}{l}\text { Escassez e comportamento } \\
\text { maximizador definem decisões } \\
\text { de produção e de compra }\end{array}$ & $\begin{array}{l}\text { Competição gera equilíbrio } \\
\text { entre oferta e demanda no nível } \\
\text { em que a receita marginal se } \\
\text { iguala ao custo marginal }\end{array}$ \\
\hline & \multirow{3}{*}{$\begin{array}{l}\text { Economia } \\
\text { Neoinstitucionalista } \\
\text { (COASE, 1993; NORTH, } \\
\text { 1990; WILLIAMSON, } \\
\text { 1985) }\end{array}$} & $\begin{array}{l}\text { O comportamento humano é } \\
\text { oportunista e baseado em } \\
\text { racionalidade limitada }\end{array}$ & \multirow{3}{*}{$\begin{array}{l}\text { Mantém o conceito de } \\
\text { competição da abordagem } \\
\text { neoclássica, porém mecanismos } \\
\text { institucionais estruturam e } \\
\text { organizam o ambiente. } \\
\text { Mercado como contraponto à } \\
\text { firma, tendo como referência a } \\
\text { eficiência transacional. }\end{array}$} \\
\hline & & $\begin{array}{l}\text { Dimensões da transação e } \\
\text { custos de governança definem a } \\
\text { escolha da forma organizacional }\end{array}$ & \\
\hline & & $\begin{array}{l}\text { Papel das instituições (regras } \\
\text { formais e informais) nas } \\
\text { decisões econômicas }\end{array}$ & \\
\hline
\end{tabular}

Competição via inovação

Economia Evolucionária (HODGSON, 1998;

NELSON; WINTER, 1982; SCHUMPETER, 1943)

Mercado como espaço das estratégias

Escola Austríaca

(HAYEK, 1941, 1945;

KIRZNER, 1973;

LANGLOIS, 1996; 2001)
Comportamento da firma pautado por regras e rotinas
Competição gera novos produtos, processos e novos mercados (lucro é a base de sustentação do processo de inovação)

Associação entre inovação, conhecimento e vantagem competitiva

Competição é geradora de desequilíbrios no mercado (variações)
Conhecimento tácito e disperso

Competição como processo social baseado no empreendedorismo

O empreendedorismo é fonte de Competição gera

mudança e inovação

Mercado como espaço sociopolítico
Escola Sociologia

Econômica

(BOURDIEU, 2005;

FLIGSTEIN, 1996;

SWEDBERG, 1994)
O mercado é institucionalizado, variando conforme as estruturas sociais e as relações de poder
Competição como processo político e socialmente estruturado, baseado em relações de poder

Diferenças de competição geram diversos mercados com identidades socioculturais distintas 
Ao contrário da visão neoclássica e neoinstitucional, a economia evolucionária e a escola austríaca apresentam uma visão de mercado em que a base da competição é a inovação. O mercado é o espaço das estratégias e não apenas de alocação de recursos. O lucro é o que move a busca por inovações geradoras de disrupções no sistema econômico (SCHUMPETER, 1943). Portanto, a competição é geradora de desequilíbrios e de heterogeneidade (HAYEK, 1945; KIRZNER, 1973); ou seja, é justamente quando o mercado "falha" que a firma atinge o seu objetivo.

Por fim, a visão do mercado como espaço sociopolítico aponta para uma abordagem do mercado em que a competição é definida pelas relações de poder. A competição é separada da arena de troca, mas de importante impacto e influência na construção, organização, mediação, regulação, reprodução, manutenção e na própria geografia do processo de troca (RANDLES, 2003).

\section{Conclusão}

No título e na introdução deste artigo é levantada a questão do por que os mercados e os governos falham. A análise das várias visões aqui apresentadas permite inferir que a resposta a essa questão reside no conceito de competição. Nota-se que tanto a visão da economia neoclássica quanto a da economia neoinstitucional se apoiam numa visão limitada de competição. É limitada, na medida em que a ênfase nos mecanismos de precificação não leva em consideração os elementos antecedentes das trocas, ou seja, o processo de competição.

$\mathrm{Na}$ análise das relações público-privadas é necessário ir além dos resultados da troca. É necessário, portanto, incluir uma visão ampla e dinâmica do processo competitivo, em que a composição de atores e a forma como estes se posicionam estrategicamente na busca de mais poder definem o resultado final das trocas.

No âmbito das visões de mercado aqui apresentadas - seja aquela que o vê como espaço das estratégias, seja aquela que o concebe como espaço sociopolítico - proporcionam, de forma articulada, uma base teórica que permite pensar o processo de competição numa perspectiva ampla e dinâmica. De um lado, a proposta de análise da visão política e sociológica, ao se apoiar nos elementos políticos e sociais do poder, enfatiza os elementos estabilizadores e geradores de barreiras de entrada. Por outro lado, a visão do processo de competição na perspectiva evolucionária e da escola austríaca permite-nos observar a dinâmica de construção e destruição das barreiras. O processo de inovação e de busca de novas soluções de mercado promove mudanças nas estruturas de mercado, e, por conseguinte, no poder de mercado.

A tese aqui defendida é a de que os mercados variam e que essa variedade decorre da própria dinâmica competitiva, sendo a competição vista numa perspectiva socioeconômica, ou seja, a de que inclui outros elementos que não o preço, como a tecnologia e o poder, sendo contextualizada socialmente. Como implicações para a gestão das relações público-privadas, sobretudo, no âmbito da regulação econômica de defesa da concorrência, essa visão da competição requer uma ênfase nas relações entre as entidades e o modo como estas evoluem ao longo do tempo.

A proposta de Bourdieu (2005) pode ser um primeiro passo nessa articulação entre a visão da economia evolucionária e a sociopolítica. Conforme assinala o autor, a capacidade de estabelecer o ritmo da transformação e o uso diferencial do tempo é um dos principais níveis do poder das firmas dominantes (líderes de mercado). É ela que é capaz de impor a representação do estilo de jogo e das regras do jogo mais favoráveis aos seus interesses, e, portanto, a sua participação no jogo e a perpetuação do mesmo. A iniciativa de mudanças no preço, ou mesmo o lançamento de novos produtos, a distribuição e a promoção, é da firma dominante.

Quanto às firmas que não são dominantes, mas que também não são pequenas, ou seja, situadas num nível abaixo do da liderança de mercado (second rank), Bourdieu afirma ser possível atacar a firma dominante e outros competidores frontalmente - por exemplo, pela redução de custos e de preços (principalmente, através da inovação tecnológica) - ou lateralmente, preenchendo os espaços deixados pela firma dominante. Entretanto, as firmas médias sempre terão lucros menores, visto que não são grandes o suficiente para explorar 
os benefícios das economias de escala e nem tão pequenas para se beneficiar de uma produção especializada, limitada a um segmento de mercado. Nesses casos, o sucesso depende da posição relativa da firma na estrutura de distribuição de capital e, por conseguinte, no campo.

Portanto, uma proposta para pesquisas futuras seria o estudo das espécies de capital e a relação entre a distribuição dessas espécies e as posições de poder, tanto do ponto de vista de compradores quanto do de vendedores. 


\section{Referências}

ALSTON, L. Empirical work in institutional economics: an overview. In: ALSTON, L. J; EGGERTSSON, T.; NORTH, D. C. (Ed.). Empirical studies in institutional change. Cambridge: Cambridge University Press, 1996.

BARBIERI, F. O processo de mercado na escola austríaca moderna. Dissertação (Mestrado em Economia ) - PósGraduação em Economia, Universidade de São Paulo, São Paulo, 2001.

BOURDIEU, P. Principles of an economic anthropology. In: SMELSER, N. J.; SWEDBERG, R. (Ed.). The handbook of economic sociology. 2nded. Princeton, N.J.: Princeton University Press; New York: Russell Sage Foundation, 2005.

COASE, R. H. The firm, the market and the law. Chicago: Chicago University Press, 1988.

. The nature of the firm. In: WILLIAMSON, Oliver; WINTER, Sidney G. (Ed.). The nature of the firm: origins, evolution and development. Oxford: Oxford University Press, 1993.

DOSI, G. Technical change and industrial transformation: the theory and an application to the semiconductor industry. London: Macmillan, 1984.

EGGERTSSON, T. A note on the economics of institutions. In: ALSTON, L. J; EGGERTSSON, T.; NORTH, D. C. (Ed.). Empirical studies in institutional change. Cambridge: Cambridge University Press, 1996.

FLIGSTEIN, N. Markets as politics: a political-cultural approach to market institutions. American Sociological Review, v.4, n.61, p.656-673, Aug. 1996.

FOSS, N. J.; FOSS, K.; KLEIN, P.; KLEIN, S. Heterogeneous capital, entrepreneurship and economic organization. Journal des Economistes et des Etudes Humaines, v. 12, n.1, p.79-96, 2002.

HARVEY, M. Competition as instituted economic process. In: METCALFE, S.; WARDE, J (Ed.). Market relations and the competitive process. [S.I.]: Manchester University Press, 2002.

HAYEK, F. A. The pure theory of capital. London: George Routledge \& Sons, 1941.

. The use of knowledge in society. The American Economic Review, v.35, n.4, p.519-530, Sep. 1945.

HODGSON, G. M. Economics and institutions: a manifesto for a modern institutional economics. [S.I.]: Cambridge Polity Press, 1988.

JOSKOW, P. L. Asset specificity and the structure of vertical relationships: empirical evidence. In: WILLIAMSON, Oliver; WINTER, Sidney G. (Ed.). The nature of the firm: origins, evolution, and development. Oxford: Oxford University Press, 1993.

KIRZNER, I. An essay on capital, New York: Augustus M. Kelley, 1966.

. Competition and entrepreneurship. Chicago: University of Chicago Press, 1973.

LACHMANN, L. M. Capital and its structure. Kansas City: Sheed Andrews and McMeel, 1978.

LANGLOIS, R. N. Strategy and the market process: introduction to the special issue. Managerial and Decision Economics, v.22, n.4/5, p.163-168, Jun./Aug. 2001.

MARSHALL, A. The principles of economics. São Paulo: Nova Cultural, 1982.

NELSON, R. R. The problem of market bias in modern capitalist economies. Industrial and Corporate Change, v.11, n.2, p.207-244, 2002.

; WINTER, S. An evolutionary theory of economic change. Cambridge: Harvard University Press. 1982.

NORTH, D. Institutions, institutional change and economic performance. Cambridge: Cambridge University Press, 1990.

PARSONS, T.; SEMELSER, N. Economy and society: a study in the integration of economic and social theory. London: Routledge and Kegan Paul, 1956.

PINDYCK, R. S.; RUBINFELD, D. L.; Microeconomia. 6.ed. São Paulo: Makron Books, 2006.

POLANYI, K. The economy as instituted process. In: POLANYI, K.; ARENSBERG, C.; Pearson, H. W. (Ed.). Trade and Market in the Early Empires: Economics in History and Theory. Glencoe, IL: Free Press, 1957. p.243-270. 
RANDLES, S. Issues for a neo-polanyian research agenda in economic sociology. International Review of Sociology, v. 13, n.2, p.409-434, July 2003.

; WARDE, A. On economic sociology, competition and markets. CRIC Discussion Paper, n.53, Aug. 2002.

RESENDE, M. Regimes regulatórios: possibilidades e limites. Pesquisa e Planejamento Econômico, v.27, n.3, 1997.

RIORDAN, M. H.; WILLIAMSON, O. Asset specificity and economic organization. International Journal of Industrial Organization, n.3, p.365-378, 1985.

SCHUMPETER, J. A. The economy as a whole - seventh chapter of the theory of economic development. Industry and Innovation, v.9, n.1/2, p.93-145, Apr./Aug. 1943.

. Capitalismo, socialismo e democracia. Rio de Janeiro: Zahar, 1984.

SWEDBERG, R. Markets as social structures. In: SMELSER, N. J.; SWEDBERG, R. (Ed.). The handbook of economic sociology. Princeton: Princeton University Press; New York: Russell Sage foundation, 1994. p.255-283.

TEECE, D. J. et al. Understanding corporate coherence: theory and evidence. Journal of Economic Behavior and Organization, v.23, p.1-30, 1994.

WALRAS, L. Compêndios dos elementos de economia política pura. São Paulo: Nova Cultural, 1996.

WILLIAMSON, O. The mechanisms of governance. Nova York: Oxford University Press, 1985.

. Comparative economic organization: the analysis of discrete structural alternatives. Administrative Science Quarterly, v.36, n.2, p.269-296, Jun. 1991.

WINTER, S. F. Understanding dynamic capabilities. Strategic Management Journal, v.24, n.10, p.991-995, Oct., 2003. 